\title{
The CNDR: Collaborating to Translate New Therapies for Canadians
}

\author{
Lawrence Korngut, Craig Campbell, Megan Johnston, Timothy Benstead, Angela \\ Genge, Alex MacKenzie, Anna McCormick, Douglas Biggar, Pierre Bourque, \\ Hannah Briemberg, Colleen O'Connell, Suzan Dojeiji, Joseph Dooley, Ian \\ Grant, Gillian Hogan, Wendy Johnston, Sanjay Kalra, Hans D. Katzberg, Jean \\ K. Mah, Laura McAdam, Hugh J. McMillan, Michel Melanson, Kathryn Selby, \\ Christen Shoesmith, Garth Smith, Shannon L. Venance, Joy Wee on behalf of the \\ CNDR Investigator Network*
}

\begin{abstract}
Background: Patient registries represent an important method of organizing "real world" patient information for clinical and research purposes. Registries can facilitate clinical trial planning and recruitment and are particularly useful in this regard for uncommon and rare diseases. Neuromuscular diseases (NMDs) are individually rare but in aggregate have a significant prevalence. In Canada, information on NMDs is lacking. Barriers to performing Canadian multicentre NMD research exist which can be overcome by a comprehensive and collaborative NMD registry. Methods: We describe the objectives, design, feasibility and initial recruitment results for the Canadian Neuromuscular Disease Registry (CNDR). Results: The CNDR is a clinic-based registry which launched nationally in June 2011, incorporates paediatric and adult neuromuscular clinics in British Columbia, Alberta, Ontario, Quebec, New Brunswick and Nova Scotia and, as of December 2012, has recruited 1161 patients from 12 provinces and territories. Complete medical datasets have been captured on 460 "index disease" patients. Another 618 "non-index" patients have been recruited with capture of physicianconfirmed diagnosis and contact information. We have demonstrated the feasibility of blended clinic and central office-based recruitment. "Index disease" patients recruited at the time of writing include 253 with Duchenne and Becker muscular dystrophy, 161 with myotonic dystrophy, and 71 with ALS. Conclusions: The CNDR is a new nationwide registry of patients with NMDs that represents an important advance in Canadian neuromuscular disease research capacity. It provides an innovative platform for organizing patient information to facilitate clinical research and to expedite translation of recent laboratory findings into human studies.
\end{abstract}

RÉSUMÉ: Le RCMN : collaborer pour procurer de nouveaux traitements aux Canadiens. Contexte : Un registre de patients est une façon très avantageuse d'organiser l'information concrète au sujet de patients à des fins cliniques ou de recherche. Les registres peuvent faciliter la planification d'essais cliniques et le recrutement et sont particulièrement utiles à cet égard quand il s'agit de maladies rares. Les maladies neuromusculaires (MNM) considérées individuellement sont des maladies rares mais elles ont une prévalence non négligeable si elles sont regroupées. Au Canada, on manque d'informations sur les MNM. Il existe des obstacles à la réalisation de recherches multicentriques sur les MNM au Canada. Ces obstacles peuvent être surmontés par l'établissement d'un registre détaillé à des fins de collaboration sur les MNM. Méthode : Nous décrivons les objectifs, le plan, la faisabilité et les résultats du recrutement initial du Registre canadien des maladies neuromusculaires. Résultats : Le RCMN est un registre basé sur la clinique qui a été inauguré à travers le Canada en juin 2011. Il inclut des cliniques neuromusculaires pédiatriques et adultes et inclut des patients de Colombie-Britannique, d'Alberta, de l'Ontario, du Québec, du Nouveau-Brunswick et de la Nouvelle-Écosse. En décembre 2012,1161 patients de 12 provinces et territoires avaient été recrutés. Des données médicales complètes sur 460 «propositi » atteints de MNM répertoriées au fichier y ont été inscrits. Six cent dix-huit autres patients qui ne sont pas des «propositi » ont été recrutés et leurs coordonnées ainsi qu'un diagnostic confirmé par un médecin ont été inscrits au registre. Nous avons démontré la faisabilité d'un recrutement mixte soit à partir de cliniques et également d'un bureau central. Les patients atteints de maladies répertoriées au registre à ce jour incluent 253 patients atteints de dystrophie musculaire de Duchenne ou de Becker, 161 patients atteints de dystrophie myotonique et 71 patients atteints de sclérose latérale amyotrophique. Conclusions : Le RCMN est un nouveau registre national de patients atteints de MNM, un progrès important en matière de capacité de recherche sur les maladies neuromusculaires au Canada. Il fournit une plateforme innovatrice pour l'organisation de l'information concernant les patients dans le but de faciliter la recherche clinique et d'accélérer le transfert des connaissances acquises récemment en laboratoire vers les études chez l'humain.

Can J Neurol Sci. 2013; 40: 698-704

\footnotetext{
From the Canadian Neuromuscular Disease Registry Investigator Network (see Appendix I for affiliations of its investigators).*

Received March 11, 2013. Final Revisions Submitted April 2, 2013.

Correspondence to: Lawrence Korngut, Clinical Neurosciences, 480060, 4th Floor Administration, South Health Campus, 4448 Front Street SE, Calgary, Alberta,

T3M 1M4, Canada. Email: lawrence.korngut@albertahealthservices.ca.
} 
The spectrum of neuromuscular disease (NMD) includes conditions that result primarily in muscle weakness and/or sensory deficits from nerve, muscle, or neuromuscular junction impairment often including central nervous system dysfunction. NMDs encompass a broad spectrum of etiologies from inherited (the muscular dystrophies) to inflammatory (Guillain-Barré syndrome), through to degenerative amyotrophic lateral sclerosis (ALS). The individual NMDs are rare but as a group are not uncommon. Moreover, common conditions such as diabetes mellitus result in secondary NMDs (e.g. diabetic polyneuropathy) that is observed in upwards of $1-2 \%$ of all people ${ }^{1,2}$ while rarer inherited NMDs collectively occur with an estimated prevalence of 1 per $2900^{3}$. ALS demonstrates a low incidence of 1-2 per 100,000/year, but the cumulative lifetime risk has been shown to be as high as 1 in $338^{4}$. The majority of patients with NMDs are diagnosed and followed in dedicated regional neuromuscular clinics (NMCs), a reflection of the expertise required in their diagnosis and management.

International efforts to organize NMD patient populations have been successful in enhancing collaborative research efforts and surmounting geographic barriers to clinical study planning and recruitment ${ }^{5}$. Canadian NMD physicians and scientists have recently been collaborating through efforts such as the Canadian Paediatric Neuromuscular Group and the Canadian ALS Network, to improve care and develop therapies for Canadians with NMDs. However, there has been a lack of infrastructure to support multi-centre collection and curation of patient information. Enhanced collaboration through the development of shared research tools and patient registries is expected to attract international clinical trials, thereby, improving access to novel therapies-in-development for Canadians ${ }^{6,7}$.

Patient registries represent an important method of collecting and organizing patient information for clinical and research purposes. Patient registries complement clinical trials by providing data that is highly generalizable or "real world." Registries can also provide accurate estimates of disease incidence and prevalence. The Northern Ireland Motor Neurone Disease project recently demonstrated a $99 \%$ completeness of ALS case ascertainment using rigorous capture-recapture methodology ${ }^{8}$. Registries can also reduce clinical study recruitment time, effort and cost through direct recruitment of registry participants potentially making countries with established registries more attractive for clinical trials?.

Development of a Canadian NMD registry is timely as in recent years a clearer understanding of disease mechanisms for several NMDs has emerged. Major advances in Duchenne (DMD), myotonic (DM), facioscapulohumeral (FSHD) muscular dystrophies and amyotrophic lateral sclerosis (ALS) have accelerated therapy development of novel molecular targets ${ }^{10-13}$. Specific causative genetic mutations have been targeted in Duchenne muscular dystrophy (DMD) with restoration of dystrophin expression. Both nonsense mutation read-through agents (eg. Ataluren, clinicaltrials.gov NCT01009294) and antisense oligonucleotide-mediated exon skipping have promising DMD human trials underway ${ }^{14,15}$. Translation of laboratory findings into clinical therapeutic applications has recently resulted in a new therapy for Pompe disease ${ }^{16}$.

In this paper we discuss the objectives, design, feasibility, and initial recruitment results of the CNDR.

\section{Methods}

\section{Objectives}

The CNDR aims to improve the future for Canadians with NMD through the enablement and support of research into potential treatments. Secondary objectives include enhancing the understanding of NMD epidemiology, addressing variations in management, and facilitating clinical knowledge translation.

\section{Neuromuscular Clinic Selection}

Paediatric and adult neuromuscular clinics across Canada were invited to participate in the CNDR. Selection criteria included: (1) demonstrated clinical focus on patients with NMD, (2) academic affiliation, and (3) interest in participating.

\section{Registry Design}

The CNDR consists of affiliated regional co-investigators and their respective neuromuscular clinics acting as clinical data collection centres. It is administered and supported centrally through the national office at the University of Calgary. Each clinic seeks local ethics approval utilizing a standardized ethics package. The CNDR National Office conducts a site initiation visit including protocol review followed by CNDR software desk-side training prior to initiation of enrollment.

\section{Organizational Structure and Scientific Expertise}

Medical and scientific expertise is provided by the CNDR Advisory Committee (CNDRAC). The CNDR Sponsors Committee (CNDRSC) is comprised of sponsors contributing significant funding to the CNDR.

A Disease Working Group (DWG) is formed for each index disease and is comprised of medical, research, basic science, and genetics experts led by a committee chair who serves on the CNDRAC. Disease Working Groups meet annually to review dataset components to maintain relevance of data collected. These experts develop the data reference manuals covering the specifications for each disease dataset.

\section{Patient Eligibility and Consent}

All Canadian residents diagnosed with a neuromuscular disease (NMD) and providing voluntary, informed consent are eligible for registration with the CNDR. The spectrum of NMDs eligible for the CNDR include those defined by the World Federation of Neurology classification of neuromuscular diseases ${ }^{17}$. Patients may provide additional consent for data transfer to the Translational Research in Europe - Assessment and Treatment of Neuromuscular Diseases (TREAT-NMD) Global Registry ${ }^{5}$, notification of research studies they may be eligible for, and for updating of their medical information on future routine visits to the clinic.

\section{Patient Recruitment}

The CNDR employs an innovative blended recruitment model enrolling subjects during routine visits at participating CNDR-affiliated NMCs in combination with direct selfregistration through the CNDR National Office for patients unable to attend affiliated clinics. The CNDR public website (http://www.cndr.org) provides information and facilitates 
recruitment through contact between interested patients and CNDR National Office staff. Importantly, any Canadian physician can refer a patient to the CNDR for enrollment either through completion of forms available through the National Office or patient self-referral.

\section{Patient Data Collection and Management}

Patient data is collected prospectively at routine clinic visits through completion of data collection forms by the attending physicians and trained data entry staff reviewing information on the patient chart. "Index" NMDs have more extensive datasets derived by national and international expert consensus ${ }^{18}$. "Nonindex" NMD datasets collect only contact information and a physician-confirmed diagnosis. The CNDR National Office monitors dataset item quality and completion rates ensuring capture of high-quality data. Data entry and quality monitoring is summarized in Appendix 2.

\section{Access to CNDR Data}

A key component of registry effectiveness is availability of data for the planning and execution of research. The CNDR has taken a novel approach enabling the release of data in two categories. All academic institution-affiliated investigators may submit research proposals requesting release of CNDR data. Following ethics review board approval at the requesting investigator's institution, research proposals are examined by a peer review committee consisting of DWG and CNDRAC members as well as other internal or external experts appropriate to the nature of the research. Research proposals are scored based on their scientific merit as well as their benefit to the patient population. Following approval, the CNDR National Office provides a customized de-identified dataset tailored to the research project needs.

The second category of data requested from the CNDR is a "statistical data request". These requests may be submitted by any third parties (i.e. pharmaceutical companies) planning studies that have not yet received ethics approval and result in provision of general CNDR statistics to facilitate study planning.

Balancing the need for data accessibility is subject privacy and confidentiality. Strict measures are in place to ensure that appropriate levels of de-identification are maintained to prevent identification of subjects at any time. Release of identified data is prohibited.

\section{Study Recruitment Through the CNDR}

The CNDR can also be used to facilitate study recruitment both locally and internationally. Researchers can submit an ethics-approved protocol for CNDR peer review. Upon research protocol and recruitment material approval the database is scanned for eligible patients. Eligible patients receive a mail-out with information regarding their eligibility for the study and contact information for the study investigators if they should choose to participate. The CNDR does not recruit patients directly for studies.

\section{The CNDR as a Clinical Tool}

The CNDR provides readily accessible patient data to local sites that has been useful to participating physicians and health care teams. CNDR index disease dataset requirements encourage review of specific patient information at routine appointments. Future studies will determine whether access to a standardized national dataset results in clinical benefits for participating patients and physicians and whether adherence to best practice standards is facilitated.

\section{Recruitment Feasibility}

Two case studies were undertaken during 2011 to assess the feasibility of patient recruitment through the CNDR clinic-based model. The first case study consisted of a single clinic enrollment model assessing ALS patient recruitment. Eligible patients were identified through ALS clinic lists and chart review. Between March 1, 2011 and February 29, 2012, ALS patients meeting at least El-Escorial criteria of Possible ALS were prospectively recruited at the Calgary ALS Clinic. It was considered that successful recruitment of $70 \%$ of known ALS patients in the clinic over the one year interval would be considered effective recruitment based on approximate patient return-to-clinic intervals and physician availability for recruitment during clinic visits.

A second case study was undertaken from March 1, 2011 through December 31, 2012 to assess feasibility of recruitment of patients with DMD. A comparison of recruited DMD patients was made to expected cases calculated from available prevalence estimates and population statistics for Canadian males aged 5- 24. Each participating paediatric NMC was attributed a proportion of each province's overall calculated cases based on relative catchment area populations from the 2010 census. The target enrollment for each clinic was then based upon the expected number of cases at that clinic based on the resulting formula (target number of DMD cases $=$ population at risk (males between and including ages 5-24 years) $\mathrm{x}$ prevalence $\mathrm{x}$ proportion of population within the clinic's catchment area). A minimum recruitment proportion exceeding $20 \%$ of expected DMD patients in the majority of included clinics was established as the feasibility criterion based upon timing of NMCs beginning recruitment, patient return-to-clinic intervals and physician availability for recruitment during clinic visits.

\section{Results}

The CNDR began patient enrollment in September 2010 with enrollment into the feasibility phase beginning March 2011 and a formal launch in June 2011.

\section{Neuromuscular Clinic Recruitment}

As of December 2012, the CNDR is comprised of twenty clinical sites in eleven academic centres (see Table 1).

At each clinic between one and four site co-principal investigators comprised of adult and paediatric neurologists and physiatrists participate in the CNDR.

\section{Recruitment Feasibility Case Studies}

The first case study examined ALS patient recruitment in the Calgary ALS Clinic. Eighty patients were identified and contacted with 68 patients providing signed informed consent for a capture proportion of $85 \%$. One patient declined enrollment 
Table 1: Adult and paediatric neuromuscular clinics participating in the CNDR

\begin{tabular}{|c|c|c|}
\hline CITY & CLINICAL SITES & ACADEMIC INSTITUTION \\
\hline Vancouver, BC & $\begin{array}{ll}- & \text { Vancouver General Hospital } \\
\text { - } & \text { BC Children's Hospital } \\
\end{array}$ & University of British Columbia \\
\hline Calgary, $\mathrm{AB}$ & $\begin{array}{ll}- & \text { Foothills Hospital } \\
\text { - } & \text { South Health Campus } \\
\text { - } & \text { Alberta Children's Hospital } \\
\end{array}$ & University of Calgary \\
\hline Edmonton, $\mathrm{AB}$ & - $\quad$ University Hospital & University of Alberta \\
\hline Mississauga, ON & $\begin{array}{ll}\text { - } & \text { ErinoakKids Centre for Treatment \& } \\
& \text { Development } \\
\end{array}$ & McMaster University \\
\hline Toronto, $\mathrm{ON}$ & $\begin{array}{ll}\text { - } & \text { University Health Network } \\
\text { - } & \text { Holland Bloorview Kids Rehabilitation Hospital } \\
\end{array}$ & University of Toronto \\
\hline London, ON & $\begin{array}{ll}- & \text { London Health Sciences Centre } \\
\text { - } & \text { Thames Valley Children's Centre } \\
\end{array}$ & Western University \\
\hline Ottawa, ON & $\begin{array}{ll}\text { - } & \text { Ottawa Hospital Rehabilitation Centre } \\
\text { - } & \text { Ottawa Hospital Civic Campus } \\
\text { - } & \text { Children's Hospital of Eastern Ontario } \\
\end{array}$ & University of Ottawa \\
\hline Kingston, $\mathrm{ON}$ & $\begin{array}{ll}\text { - } & \text { Kingston General Hospital } \\
\text { - } & \text { Child Development Centre, Hotel Dieu Hospital } \\
\text { - } & \text { Providence Care - St. Mary's of the Lake } \\
\end{array}$ & Queen's University \\
\hline Montreal, QC & - $\quad$ Montreal Neurological Institute & McGill University \\
\hline Halifax, NS & $\begin{array}{ll}- & \text { Halifax Infirmary } \\
\text { - } & \text { IWK Health Centre } \\
\end{array}$ & Dalhousie University \\
\hline Fredericton, NB & - $\quad$ Stan Cassidy Centre for Rehabilitation & University of New Brunswick/Dalhousie University \\
\hline
\end{tabular}

with the remaining patients being undecided, deceased or lost to follow up. It was felt that the high capture proportion demonstrated feasibility of ALS subject recruitment through a clinic-based registry design. It is expected that near or complete case ascertainment is achievable via in-clinic, telephone and mail-out patient contact.

The second case study examined DMD recruitment across five paediatric clinics (see Table 2). We used a previously published minimum prevalence estimate of 1.3/10,000 males aged $5-24^{19}$ based on data from four US states which is supported by Canadian findings of 1.5/10,000 males aged $0-24$ based on dystrophin mutation analysis ${ }^{6}$. The CNDR has set the goal of complete ascertainment of this lower incidence estimate in its clinics by March 31, 2013. During the recruitment interval 217 patients with DMD were recruited in the five clinics comprising $112.4 \%$ of the March 2013 population-based recruitment target of 193 patients.

\section{Overall Recruitment}

To date the CNDR has recruited 1161 patients from twelve of the thirteen provinces and territories while having clinics in only 6 provinces (see Table 3). Of the 1161 patients, 543 (47\%) are

Table 2: Projected DMD recruitment targets in CNDR clinics and actual recruitment

\begin{tabular}{|c|c|c|c|c|c|c|}
\hline Province & $\begin{array}{c}\text { Male population } \\
\text { age } 5-24 \text { (as of } \\
\text { July } 1,2010- \\
\text { Statistics } \\
\text { Canada) }\end{array}$ & $\begin{array}{c}\text { Minimum } \\
\text { Prevalence } \\
\text { Estimate } \\
(\mathbf{1 . 3 / 1 0 , 0 0 0} \\
\text { males }) \\
\end{array}$ & $\begin{array}{l}\text { Estimated pediatric } \\
\text { clinic capture (\% of } \\
\text { provincial total) }\end{array}$ & $\begin{array}{c}\text { DMD } \\
\text { Population } \\
\text { Target (March } \\
\mathbf{3 1 , 2 0 1 3 )}\end{array}$ & $\begin{array}{c}\text { Actual } \\
\text { Recruitment } \\
\text { (December } \\
\text { 31, 2012) }\end{array}$ & $\begin{array}{c}\text { Proportion } \\
\text { Recruited } \\
\text { (Between March } \\
2011 \text { and } \\
\text { December 2012) }\end{array}$ \\
\hline Alberta & 496,657 & 65 & Calgary $-56.41 \%$ & 37 & 29 & $78.4 \%$ \\
\hline $\begin{array}{l}\text { British } \\
\text { Columbia }\end{array}$ & 554,042 & 72 & Vancouver $-100 \% *$ & 72 & 56 & $77.8 \%$ \\
\hline \multirow[t]{5}{*}{ Ontario } & \multirow[t]{5}{*}{$1,692,014$} & \multirow[t]{5}{*}{220} & London $-7.60 \%$ & 17 & 50 & $294.1 \%$ \\
\hline & & & Ottawa $-9.37 \%$ & 21 & 25 & $119.0 \%$ \\
\hline & & & Mississauga $-8.67 \%$ & 19 & 9 & $47.4 \%$ \\
\hline & & & Toronto $-8.60 \%$ & 19 & 35 & $184.2 \%$ \\
\hline & & & Kingston $-3.57 \%$ & 8 & 13 & $162.5 \%$ \\
\hline TOTAL & $2,742,713$ & 357 & $46 \%$ & 193 & $217 * *$ & $112.4 \%$ \\
\hline
\end{tabular}

*only neuromuscular clinic in the province; **one DMD patient was recruited through the national office for a total of 218 patients. 
Table 3: Subjects recruited as of December 31, 2012 by disease

\begin{tabular}{|c|c|c|c|}
\hline Index Disease & Number of Subjects & Non-Index Disease & Number of Subjects \\
\hline Duchenne muscular dystrophy & 218 & ALS & 108 \\
\hline Becker muscular dystrophy & 35 & $\begin{array}{l}\text { Myasthenia gravis (all types) } \\
\text { Charcot-Marie Tooth (all types) } \\
\text { Spinal muscular atrophy }\end{array}$ & $\begin{array}{l}61 \\
54\end{array}$ \\
\hline Intermediate dystrophinopathy & 4 & Limb-girdle muscular dystrophy (all types) & $\begin{array}{l}52 \\
47\end{array}$ \\
\hline $\begin{array}{c}\text { Manifesting female } \\
\text { dystrophinopathy carriers }\end{array}$ & 7 & & \\
\hline $\begin{array}{l}\text { Myotonic muscular dystrophy } \\
\text { (type } 1 \text { and 2) }\end{array}$ & 161 & Facioscapulohumeral muscular dystrophy & 46 \\
\hline Guillain-Barré syndrome & 21 & & \\
\hline ALS & 57 & $\begin{array}{l}\text { Inclusion body myositis } \\
\text { Oculopharyngeal muscular dystrophy }\end{array}$ & 21 \\
\hline Incomplete & 40 & Primary lateral sclerosis & $\begin{array}{l}16 \\
15\end{array}$ \\
\hline \multirow[t]{2}{*}{ Total Index } & 543 & & \\
\hline & & $\begin{array}{c}\text { Chronic inflammatory demyelinating } \\
\text { polyneuropathy } \\
\text { All other diseases } \\
\end{array}$ & $\begin{array}{l}15 \\
183 \\
\end{array}$ \\
\hline Total Subjects & 1161 & Total Non-Index & 618 \\
\hline
\end{tabular}

index disease patients with 218 being DMD, and $161 \mathrm{DM}$. The other index diseases include Becker muscular dystrophy, Intermediate muscular dystrophy, ALS, and Guillain-Barré syndrome. The remaining 618 patients are "non-index" patients representing over 20 neuromuscular conditions. In 2012, ALS was added as an index disease transitioning from the non-index group and some patients are still in the process of being reconsented. In 2013, the CNDR will transition SMA from the non-index group to the index group. The largest non-index populations are: ALS (108), myasthenia gravis (61), CharcotMarie Tooth (54), SMA (52), limb girdle muscular dystrophy (47) and FSHD (46) patients. Within the next two years the CNDR aims to recruit 4000 patients across Canada.

\section{Facilitating Clinical Research}

Through December 31, 2012, the CNDR provided deidentified data for two clinical trial feasibility requests approved by the TREAT-NMD Alliance. The CNDR has notified patients for two peer-reviewed academically funded studies, and a third study was recently approved. In one study examining NMD and occupational status 189 information letters were mailed to adult patients. For the second study, 639 information letters were mailed to adults and parents of children age 5-16 with chronic neurologic diseases for a large cross sectional quality of life study. The CNDR has also facilitated site selection for one additional pharmaceutical industry inquiry and provided deidentified statistical information for three additional investigator or industry initiated inquiries. This is a total of nine inquiries since June 2011.

\section{CONClusions}

The CNDR is a Canada-wide registry of patients with neuromuscular disease. Using an innovative approach to organization of patient information through a blended patient recruitment model, the CNDR has enrolled patients from 12 provinces and territories. The CNDR is providing access to data through a rigorous peer-review process to maximize availability of the data to the international research community and is a new data source for examining potential disparities between provincial health care systems. Through accurate and comprehensive prospective data collection the CNDR is anticipated to facilitate clinical research, expedite clinical trials, and provide important epidemiological insights while improving access to novel therapies for Canadians with NMD.

\section{Sustainability}

The CNDR has been funded through contributions from the ALS Society of Canada (Toronto, Ontario), the Families of Spinal Muscular Atrophy Canada Society (Chilliwack, British Columbia), Jesse's Journey (London, Ontario) and the Marigold Foundation (Calgary, Alberta) as well as individual private donations. The single infrastructure, multi-disease model permits sponsor cost-sharing for central operating costs and direct allocation of disease-specific funds to specific NMCs for data entry. Alternative data entry technology is currently being examined to enhance data entry quality and reduce cost. To date, members of the CNDR Investigator Network have applied for five research grants to fund national level multi-centered NMD research projects using the CNDR infrastructure for data collection with appropriate CNDR-allocated budget incorporated into each submission. Pharmaceutical company inquiries will be provided data for clinical trial planning and recruitment on a cost-recovery basis. The CNDR will also be examined as a Phase IV post-approval monitoring tool. The combination of these strategies is expected to result in a sustainable operating budget in the long term. 


\section{Limitations}

Patient registries provide the most generalizable epidemiological and outcome data when case ascertainment is complete. Registry data that are not population-based increase the risk of recruitment bias and study findings not representing the overall affected population. Other clear limitations to registry methodology include the time and financial burdens associated with informed consent requirements which are an essential component of conducting clinical research. At this time, the CNDR does not include all Canadian NMCs and as a result patients will not be uniformly recruited across Canada. While the ultimate aim of the CNDR is to evolve into a national population-based registry with complete ascertainment of patients with specific index NMDs, the initial goal is to demonstrate complete ascertainment in multiple provinces beginning in 2013. The limited number of NMCs in provinces such as Nova Scotia (2) and British Columbia (2) suggest this goal is realistic. Data linkage to administrative sources and validation of population-based status will be pursued.

The CNDR is a highly collaborative network of investigators, actively engaged with non-profit and charitable organizations as sponsors, sharing a vision of improving the lives of those with NMD in Canada.

\section{ACKNOWLEDGEMENTS}

The authors thank Dr. Samuel Wiebe, Dr. Nathalie Jetté, and Ms. Janet Warner (University of Calgary, Calgary, Alberta) for their contributions to this manuscript.

\section{REFERENCES}

1. Shaw JE, Sicree RA, Zimmet PZ. Global estimates of the prevalence of diabetes for 2010 and 2030. Diabetes Res Clin Pract. 2010;87(1):4-14.

2. Karvestedt L, Martensson E, Grill V, et al. The prevalence of peripheral neuropathy in a population-based study of patients with type 2 diabetes in Sweden. J Diabetes Complications. 2011; 25(2):97-106.

3. Hughes MI, Hicks EM, Nevin NC, Patterson VH. The prevalence of inherited neuromuscular disease in Northern Ireland. Neuromuscular disorders: NMD. 1996;6(1):69-73.

4. Johnston CA, Stanton BR, Turner MR, et al. Amyotrophic lateral sclerosis in an urban setting: a population based study of inner city London. J Neurol. 2006;253(12):1642-3.
5. Bushby K, Lynn S, Straub T, TREAT-NMD Network. Collaborating to bring new therapies to the patient--the TREAT-NMD model. Acta Myol. 2009;(1):12-15.

6. Mah JK, Selby K, Campbell C, et al. A population-based study of dystrophin mutations in Canada. Can J Neurol Sci. 2011 May; 38(3):465-74.

7. Aggarwal SP, Zinman L, Simpson E, et al. Safety and efficacy of lithium in combination with riluzole for treatment of amyotrophic lateral sclerosis: a randomised, double-blind, placebo-controlled trial. Lancet Neurol. 2010;9:481-8.

8. Donaghy C, Clarke J, Patterson C, Kee F, Hardiman O, Patterson V. The epidemiology of motor neuron disease in Northern Ireland using capture-recapture methodology. Amyotroph Lateral Scler. 2010;(4):374-8.

9. Lijovic M, Davis SR, Fradkin P, et al. Use of a cancer registry is preferable to a direct-to-community approach for recruitment to a cohort study of wellbeing in women newly diagnosed with invasive breast cancer. BMC Cancer. 2008;8:126.

10. Lemmers RJLF, van der Vliet PJ, Klooster R, et al. A unifying genetic model for facioscapulohumeral muscular dystrophy. Science. 2010;329(5999):1650-3.

11. Deng H-X, Chen W, Hong S-T, et al. Mutations in UBQLN2 cause dominant X-linked juvenile and adult-onset ALS and ALS/dementia. Nature. 2011;477(7363):211-15.

12. Strong MJ. The evidence for altered RNA metabolism in amyotrophic lateral sclerosis (ALS). J Neurol Sci. 2010;288(12):1-12.

13. López Castel A, Cleary JD, Pearson CE. Repeat instability as the basis for human diseases and as a potential target for therapy. Nat Rev Mol Cell Biol. 2010 March;11(3):165-70.

14. Kinali M, Arechavala-Gomeza V, Feng L, et al. Local restoration of dystrophin expression with the morpholino oligomer AVI-4658 in Duchenne muscular dystrophy: a single-blind, placebocontrolled, dose-escalation, proof-of-concept study. Lancet Neurol. 2009;8(10):918-28.

15. Goemans NM, Tulinius M, van den Akker JT, et al. Systemic administration of PRO051 in Duchenne's muscular dystrophy. N Engl J Med. 2011 April 4;364(16):1513-22.

16. Kishnani PS, Corzo D, Leslie ND, et al. Early treatment with alglucosidase alpha prolongs long-term survival of infants with Pompe disease. Pediatr Res. 2009 September;66(3):329-35.

17. Rowland LP, Mcleod JG. Classification of neuromuscular disorders. J Neurol Sci. 1994;124:109.

18. Thompson R, Schoser B, Monckton DG, Blonsky K, Lochmüller H. Patient Registries and Trial Readiness in Myotonic Dystrophy--TREAT-NMD/Marigold International Workshop Report. Neuromuscular disorders: NMD. 2009;19(12):860.

19. Centers for Disease Disease, Control, Prevention. Prevalence of Duchenne/Becker muscular dystrophy among males aged 5-24 years - four states, 2007. MMWR Morb Mortal Wkly Rep. 2009;58(40):1119-22. 


\section{APPENDIX I*}

The CNDR Investigator Network is comprised of all investigators who have contributed time and expertise in developing the CNDR protocol, data sets and/or documentation.

National Principal Investigator - Lawrence Korngut (University of Calgary); National Project Manager - Megan Johnston (University of Calgary); Advisory Committee - Craig Campbell (Paediatric Expert; Western University), Timothy Benstead (Adult Expert; Dalhousie University), Angela Genge (ALS Expert; McGill University), Alex MacKenzie (SMA Expert, University of Ottawa), Anna McCormick (DMD expert; University of Ottawa); Site Co-Principal Investigators - Timothy Benstead (Dalhousie University), Douglas Biggar (Holland Bloorview Kids Rehabilitation Hospital, University of Toronto), Pierre Bourque (University of Ottawa), Hannah Briemberg (University of British Columbia), Vera Bril (University of Toronto), Craig Campbell (Western University), Alan Casey (University of Manitoba), Neil Cashman (University of British Columbia), Kristine Chapman (University of British Columbia), Colleen O'Connell (Stan Cassidy Centre for Rehabilitation), Suzan Dojeiji (University of Ottawa), Joseph Dooley (Dalhousie University), Nicolas Dupre (Laval University), Gillian Gibson (University of British Columbia), Ian Grant (Dalhousie University), Walter Hader (University of Saskatchewan), Gillian Hogan (ErinoakKids Centre for Treatment and Development), Wendy Johnston (University of Alberta), Sanjay Kalra (University of Alberta), Hans D. Katzberg (University of Toronto), Charles Krieger (University of British Columbia), Edward Leung (University of Manitoba), Jean K. Mah (University of Calgary), Laura McAdam (Holland Bloorview Kids Rehabilitation Hospital, University of Toronto), Anna McCormick (University of Ottawa), Hugh McMillan (University of Ottawa), Michel Melanson (Queen's University), Michelle M. Mezei (University of British Columbia), Kerri Schellenberg (University of Alberta), Kathryn Selby (University of British Columbia), Christen Shoesmith (Western University), Garth Smith (Queen's University), Shannon L. Venance (Western University), Joy Wee (Queen's University), Scott Worley (Stan Cassidy Centre for Rehabilitation, Dalhousie University), Lorne Zinman (University of Toronto). DMD Working Group - Craig Campbell (Paediatric Expert; University of Western Ontario), Gillian Hogan (Working Group Member, ErinoakKids Centre for Treatment and Development), Jean K. Mah (Working Group Member, University of Calgary), Laura McAdam (Working Group Member, Holland Bloorview Kids Rehabilitation Hospital), Anna McCormick (Working Group Lead, University of Ottawa) Peter Ray (DMD Genetics Expert, University of Toronto), Kathryn Selby (Working Group Member, University of British Columbia), ALS Working Group - Colleen O'Connell (University of New Brunswick), Angela Genge (Working Group Lead; McGill University), Christen Shoesmith (University of Western Ontario), SMA Working Group - Craig Campbell (Paediatric Expert; University of Western Ontario), Alex MacKenzie (Working Group Lead, University of Ottawa), Maryam Oskoui (Working Group Member; McGill University), Kathryn Selby (Working Group Member, University of British Columbia), Louise Simard (Working Group Member, University of Manitoba), Jiri Vajsar (Working Group Member, University of Toronto).

\section{APPENDIX II}

Data is entered through a secure portal interface accessible from any desktop computer with Internet access and then sent via secure socket layer (SSL) transmission over the Internet to a secure data server housed at the University of Calgary. Local data collection forms are maintained as source documents for review at annual audit visits by CNDR National Office staff. Specific requirements for individual dataset fields are outlined in data reference manuals. Data entry is reviewed weekly at the National Office to ensure data standard compliance. Detected errors are logged and reported to site data-entry personnel for correction. Data entry personnel have the opportunity to attend semi-monthly data support teleconferences with CNDR National Office staff to troubleshoot common problems and discuss data entry anomalies noted at the national office enhancing future data entry quality. Regular data audits will be performed beginning in mid-2012. 